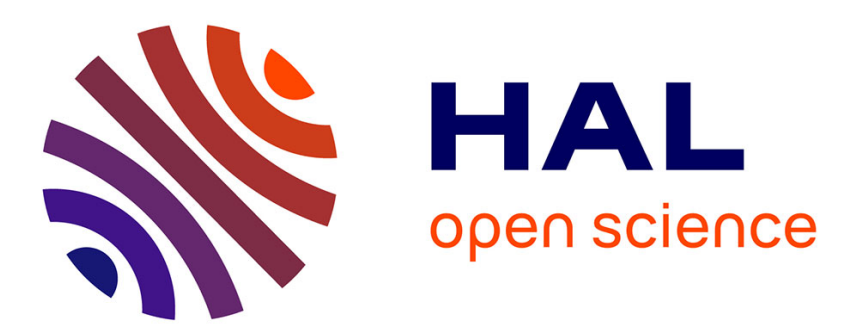

\title{
The Influence of a Degree of Initial Material Defects on the Strain Structure Formed in the Explosive Collapsing Thick-Walled Cylinders
}

\author{
M. Bondar, Ya. Lukyanov, T. Teslenko
}

\section{- To cite this version:}

M. Bondar, Ya. Lukyanov, T. Teslenko. The Influence of a Degree of Initial Material Defects on the Strain Structure Formed in the Explosive Collapsing Thick-Walled Cylinders. Journal de Physique IV Proceedings, 1997, 07 (C3), pp.C3-481-C3-486. 10.1051/jp4:1997383 • jpa-00255540

HAL Id: jpa-00255540

https://hal.science/jpa-00255540

Submitted on 1 Jan 1997

HAL is a multi-disciplinary open access archive for the deposit and dissemination of scientific research documents, whether they are published or not. The documents may come from teaching and research institutions in France or abroad, or from public or private research centers.
L'archive ouverte pluridisciplinaire HAL, est destinée au dépôt et à la diffusion de documents scientifiques de niveau recherche, publiés ou non, émanant des établissements d'enseignement et de recherche français ou étrangers, des laboratoires publics ou privés. 


\title{
The Influence of a Degree of Initial Material Defects on the Strain Structure Formed in the Explosive Collapsing Thick-Walled Cylinders
}

\author{
M. Bondar, Ya.L. Lukyanov and T. Teslenko \\ Lavrentyev Institute of Hydrodynamics, Lavrentyev Avenue 15, Novosibirsk 630090, Russia
}

\begin{abstract}
The influence of preliminary shock-wave loading on the deformation structure formation in the process of following high-rate plastic strain has been investigated. The previous hardening is shown to provide a structural uniformity of the deformation to large value of strain due to the formation of a highly dispersed intergrain structure.
\end{abstract}

Résumé: L'influence de chargement préliminaire par ondes de choc sur la formation de la structure déformée lors de la déformation plastique ultérieure à grande vitesse de déformation est étudiée. On démontre que le chargement préliminaire détermine l'uniformité structurale de la déformation jusqu'à des valeurs très élevées grâce à la création d'une structure intergranulaire fortement dispersive.

\section{INTRODUCTION}

The investigation of structure-deformational states of metals under explosive loading, followed by large plastic deformations, is of interest. At present the mechanism of deformation and its dependence on the medium nature and structural parameters have not been studied extensively. The influence of the initial structural state on deformation processes under high-rate loading is shown in a variety of papers [1 - 3]. However, an alternative geometry of loading as well as other initial states of source materials and insufficient quantity of experimental data give no way of developing now the general dependences.

This paper deals with the influence of previous hardening, produced by the plain shock-wave loading, on the deformation structure formed during the explosive collapse of hollow thick-walled cylinder (TWC). The use of the TWC method is conditioned by the fact that the cylindrical geometry allows one to calculate the continual strain value of a material by the values of the initial and final radii providing of the material incompressibility. Moreover, one can define a strain and strain rate fields by measuring inside surface velocity of cylinder [4].

A comparison of the structure with the strain value allows one to judge the mechanism and kinetics of structure formation process. The type of deformation realized during TWC collapse consists in the compression shear typical for the explosive welding and compaction. Therefore, the deformation conformities established during TWC collapse can be considered using the above processes.

This method used previously has enabled one to recognize that the critical parameters $(\varepsilon, \dot{\varepsilon})$, which determine the onset of plastic deformation localization and crack formation depend highly on the grain size in an initial material [1].

A vacuum melting copper having grain sizes 60 and $3000 \mu \mathrm{m}$ has been used in experiments. Previous hardening has been performed with the samples in the form of a disk with diameter of $30 \mathrm{~mm}$ and $10 \mathrm{~mm}$ thick. The hardening is carried out by the plane shock wave generator [5] and explosive charge made of the composition TNT + RDX $50 / 50$ with thickness of $10 \mathrm{~mm}$. According to our calculations, the pressure in the samples varies from contact the surface to the depth of $30 \mathrm{~mm}$ from 32 to $24 \mathrm{GPa}$ [5]. The residual deformation does not exceed $5 \%$.

The samples for the high-rate deformation ate made as a cylinders with the central part involving 3 pre-hardened disks having the same grain size. These cylinders are supplemented to the overall length 70 mm with unhardened copper having the same grain size. This set of samples allows one most exactly to 
establish the role of the previous hardening in the deformation structure formation in the collapse process.

The collapse of cylinders is produced by detonation of a coaxial explosive charge situated at the outer surface of the cylinder. The direction of detonation is parallel to the axis of cylinders. The wall thickness of copper cylinder is $8.5 \mathrm{~mm}$, the bore diameter is $12.5 \mathrm{~mm}$. The explosive parameters (density - $1 \mathrm{~g} / \mathrm{cml}$. detonation velocity $-3700 \mathrm{~m} / \mathrm{s}$ ) and its size (outside diameter is $60 \mathrm{~mm}$ ) are carefully selected in order to avoid a jet formation on collapsing. Experimentally, the strain rate varies in the range from $3.5 \cdot 10^{4}$ to $3.9 \cdot 10^{4} \mathrm{~s}^{-1}$. The microstructure of samples is tested by optical and X-ray methods. The hardening degree is defined by changing a microhardness.

\section{RESULTS}

The microstructure of collapsed samples is studied on polished surfaces which planes are spaced normal to the axis of the cylinder. The investigations have shown that the structure nature changes along the cylinder radius for fine-grained samples is independent of initial conditions. There is no evidence of a deformation localization in these samples before cracking, as demonstrated by not only the uniform structure of a flow. but also equal microhardness values near to the crack end and at adjacent sites (Fig. 1). However, the structure at the end of cracks points to peculiarities manifested which can be precursors of plastic defor. mation localization. Characteristics of all types of samples are the intensive deformation of grains. This deformation shows up in the change of grain shapes, stretched to the centre as well as in the appearance of deformation lines centrally undirected in the grains (Fig. 1). The strain value fitting the onset of intensive structural texturing is determined.

In Table 1 the experimental data are listed. It is evident that intensive unidirectional flow in pre. hardened samples begins with the large continual strain value. The residual diameters of inside holes measured in the polished surfaces are also presented in the Table 1. There is a difference between their value for pre-hardened and unhardened samples.

Table 1 .

\begin{tabular}{|c|c|c|c|c|}
\hline \multicolumn{2}{|c|}{ Sample character } & \multirow{2}{*}{$\begin{array}{l}\varepsilon \text { of the onset in- } \\
\text { tensive deformation }\end{array}$} & \multirow{2}{*}{$\begin{array}{l}\varepsilon \text { at the boundary } \\
\text { of change } H v_{\text {average }}\end{array}$} & \multirow{2}{*}{$\begin{array}{c}\text { Final hole } \\
\text { diameter, } \mathrm{mm}\end{array}$} \\
\hline grain size & state & & & \\
\hline \multirow{3}{*}{$>1000$} & unhardened & 0.30 & 0.50 & 0.85 \\
\hline & hardened & 0.50 & 1.02 & 0.43 \\
\hline & unhardened & 0.40 & 0.47 & 0.2 \\
\hline 60 & hardened & 0.64 & 1.01 & 0.75 \\
\hline
\end{tabular}

The deformation features of pre-hardened coarse-grained samples should be noted. Beginning with the periphery, the actively developed sliding lines followed by faulting in the area of the intensive plastic flow. are observed in all grains. Conversely, for the unhardened samples, the deformation in grains is observed, beginning with a localized flow (Fig 1). In addition, coarse-grained samples differ from fine-grained ones in that a final hole diameter in hardened samples is less than in unhardened.

The microhardness is measured under a load $P=50 \mathrm{~g}$. The results are plotted in Fig. 2 . It is easily seen. that each sample has two well-defined areas with different average microhardness values. The boundaries between these areas in values of strain appropriate to them are presented in Table 1. The change of microhardness at a distance of $4 \mathrm{~mm}$ from the centre is remarkable for all curves. This distance corresponds to transition boundary from tensile to compressive stresses [6]. The average microhardness in periphery areas diminishes more progressively than the average microhardness of shock-loaded material $H v_{\text {hard }}$.

The X-ray investigation of collapsed samples has revealed the deformation texture unavailable in the initial samples. The texture type is determined. The plane of the axial section of the cylinder is (110); the direction to the centre is $<112>$. This is a typical structure of rolling copper providing the plane passes through the cylinder axis on coming in contact with the rolling plane. When collapsing, the maximum conlpressive stresses actually are normal to this plain. The texture type is found to be unaffected by the previous hardening. The texture is fixed in the cylinder sections beginning with $6-7 \mathrm{~mm}$ from the centre $(\varepsilon=$ 


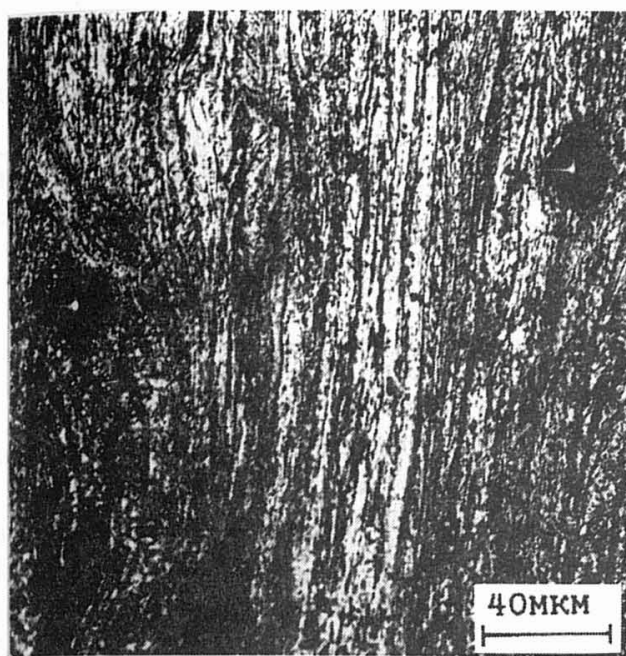

Ia
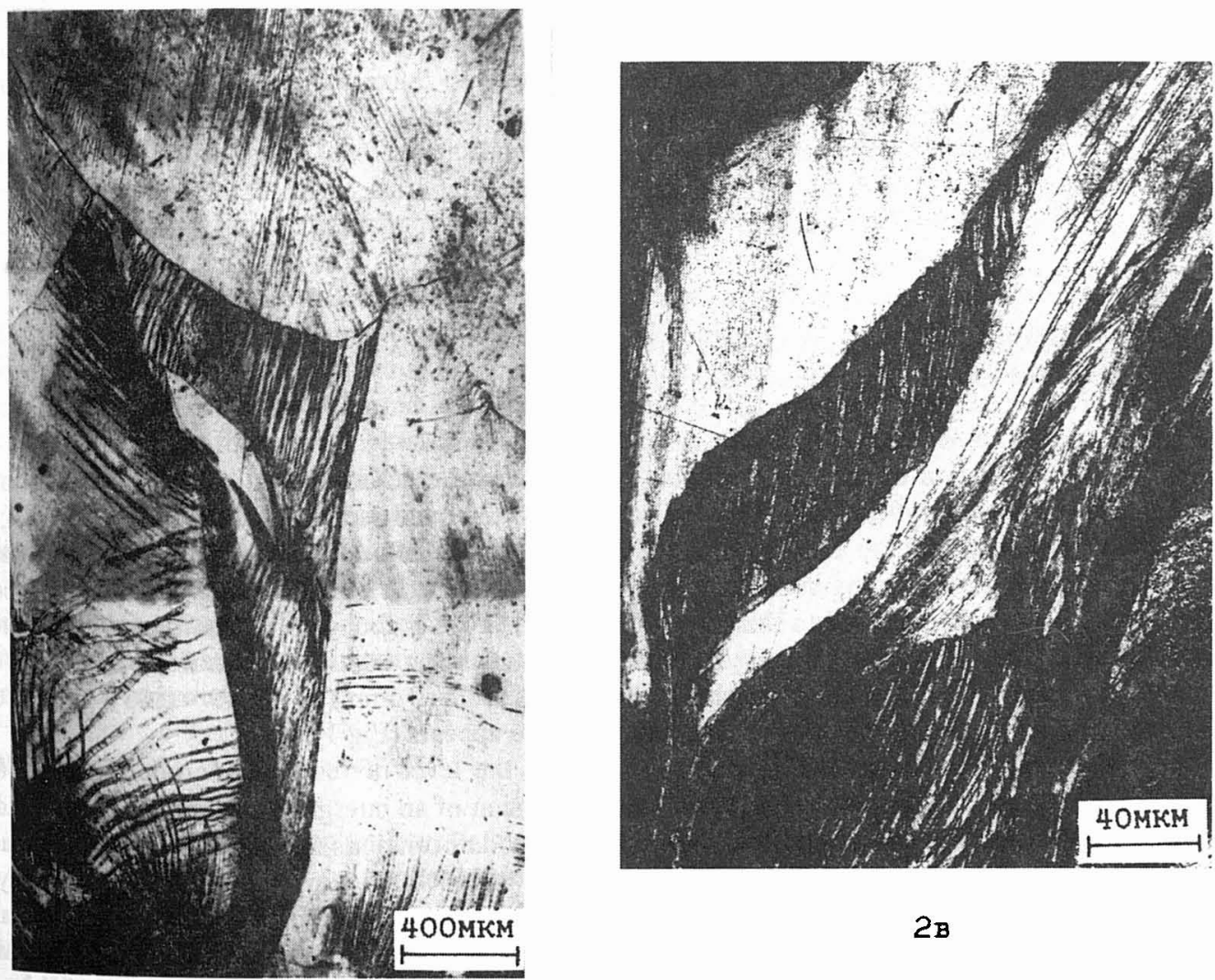

$2 B$

Wh

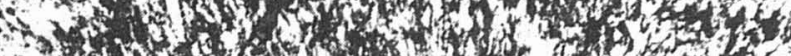
3.6. (5)

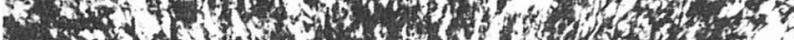

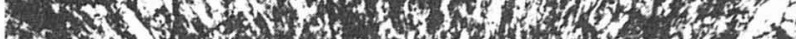

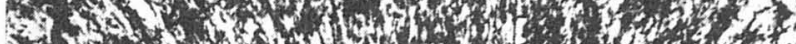
B.

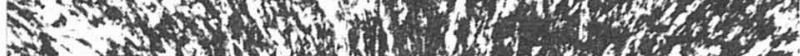

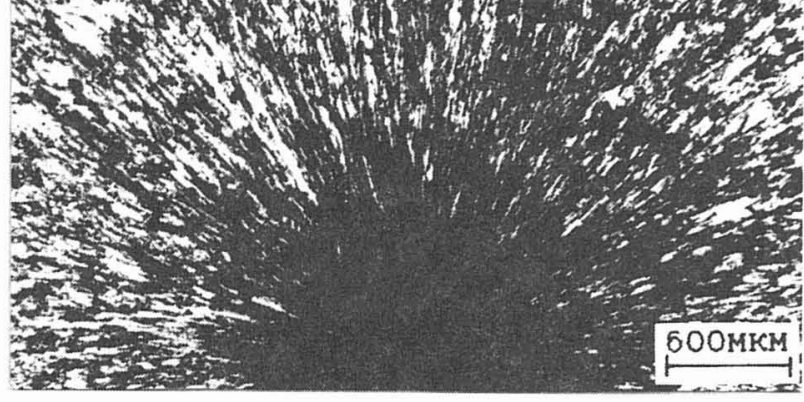

IB

$2 a$

Fig 1. The microstructure in vicinity of the central hole. $1 .-d=60 \mu \mathrm{m}$ a - microsructural features of localization, $\mathrm{b}$ - general features. 2. $d>1000 \mu \mathrm{m}$ a - the onset of localizaton plastic deformation in the unhardened sample, $b$ - fault bands in the hardening samples. 
$0.30-0.40)$, and strengthened with approaching the centre to $2-3 \mathrm{~mm}(\varepsilon=1.19-0.83)$, and affected near the centre where a micro-grained recrystallized structure appears (Fig 1).

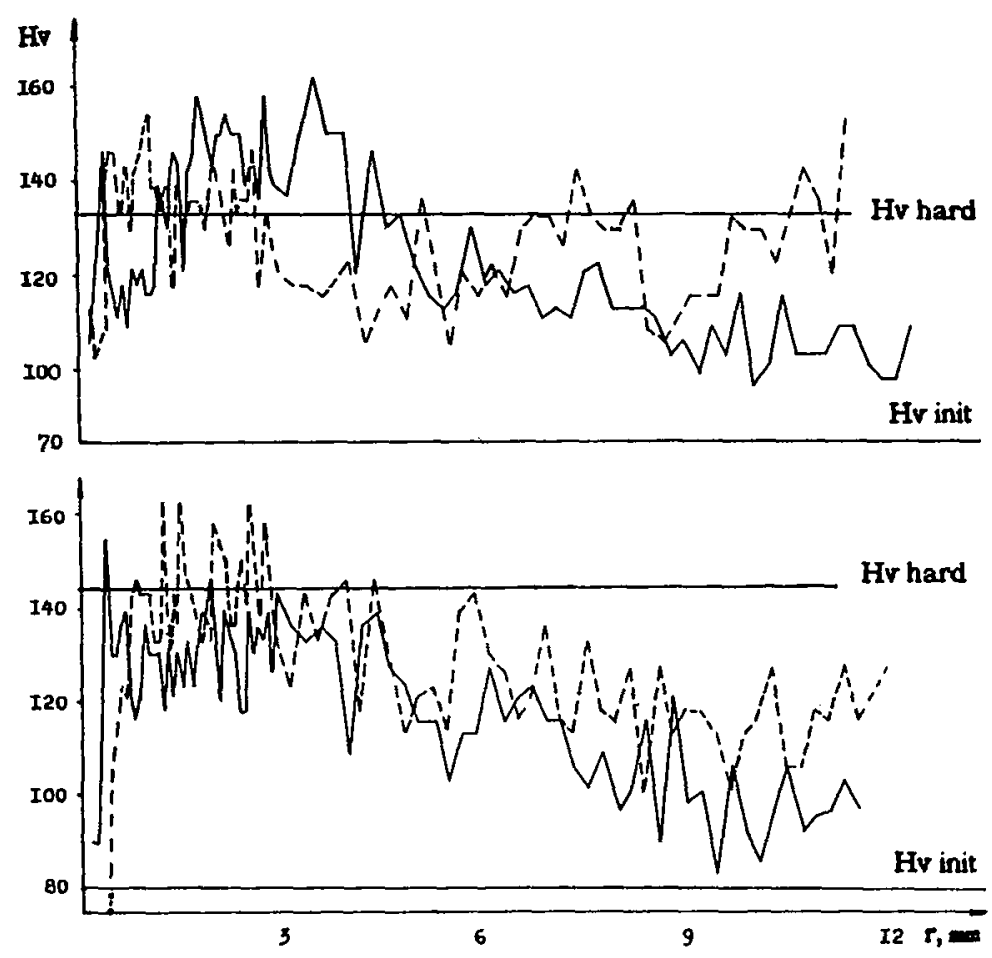

Fig. 2. The microhardness as a function of distance from the central axis of collapsed cylinder, a $-d>1000 \mu \mathrm{m}, \mathrm{b} \sim d=60$ $\mu \mathrm{m}$, dash line - hardened samples $\left(H v_{\text {hard }}\right)$, clean line - unhardened samples $\left(H v_{\text {inir }}\right)$.

The X-ray investigation of collapsed samples has revealed the deformation texture unavailable in the initial samples. The texture type is determined. The plane of the axial section of the cylinder is (110); the direction to the centre is $<112>$. This is a typical structure of rolling copper providing the plane passes through the cylinder axis on coming in contact with the rolling plane. When collapsing, the maximum comtpressive stresses actually are normal to this plain. The texture type is found to be unaffected by the previous hardening. The texture is fixed in the cylinder sections beginning with $6-7 \mathrm{~mm}$ from the centre $(\varepsilon=$ $0.30-0.40)$, and strengthened with approaching the centre to $2-3 \mathrm{~mm}(\varepsilon=1.19-0.83)$, and affected near the centre where a micro-grained recrystallized structure appears (Fig 1).

The changes of such microstructure characteristics as the level of residual microdeformations of a crystal lattice $\Delta a / a$ ( $a$ is the lattice parameter) and the dispersion of an intergrain structure $(D \mu)$ are studied by the $\mathrm{X}$-ray diffraction line breadthing method. All the microdeformations are basically due to the chaotically distributed defects, of a crystal lattice. The dispersion of block structure may define the quantity of subboundaries having disorientation, suffices for incoherently participating adjacent areas of the crystal in scattering. In Table 2 are listed the values of the substructure characteristics obtained for fine-grained samlples after plane shock loading on collapsing cylinders and for comparison, of samples unaffected by the previous hardening, on collapse too. 
Table 2.

\begin{tabular}{l|cccc}
\hline State of sample & $\begin{array}{c}\text { Distance from } \\
\text { the centre, } \mathrm{mm}\end{array}$ & $\begin{array}{c}D \mu, \\
\mu \mathrm{m}\end{array}$ & $\Delta a / a \cdot 10^{3}$ & $\begin{array}{c}H \nu \\
\mathrm{kg} / \mathrm{mm}^{2}\end{array}$ \\
\hline shock-wave hardening & all sample & -- & 1.4 & 142 \\
shock-wave hardening & $1.5-3.0$ & 0.11 & 0.95 & 140 \\
+ collapse & $>5.0$ & $0.15-0.18$ & $0.35--0.6$ & 125 \\
collapse & $1.5-3.0$ & 0.2 & 0.7 & 140 \\
collapse & $>5.0$ & 0.22 & $0.3-0.5$ & 115 \\
\hline
\end{tabular}

The plane shock-wave loading produces a unique structure, which is absent in the other processes. The structure has the highest density of chaotic distributed defects with no evidence of a block structure.

The principal effect of the following high-rate plastic deformation on collapse is the formation of subboundaries and fragmentation of the intergrain structure, which is evident from Table 2. The size of blocks decreases with increasing a strain and strain rate, $i$. e. is a quantity of subboundaries increases, and the vahe $\Delta a / a$, responsible for chaotically distributed defects decreases as against that for shock-loaded samples. On shock-wave loading the structural state characterized by the high density of chaotically distributed defects is of high-energy and thus the state is unstable. The redistribution of the defects, namely, the formation of low-energy dislocation structures (block) takes place during the following high-rate plastic deformation. These processes can lead to the softening of a material. This fact can explain the decrease of the microhardness observed in peripheries of collapsed shock-loaded samples as against its value before collapse. This cannot be caused by thermal softening owing to a low deformation degree of the sample periphery. lncreasing the microhardness in the area situated nearer to the centre, is due to the limiting fragmentation of structure given the maximum value of the strain and strain rate. The comparison of the deformation structure features in the previous hardened and unhardened samples (a different value of $\varepsilon$, whereby the intensive directed flow begins) testifies that the defective structure produced by shock wave loading provides the conditions for forming the intergrain block structure during the following plastic deformation. This structure facilitates the rotational type of deformation to relatively large values of $\varepsilon$ resulting under uniform deformation at given $\varepsilon$.

The difference in structures and the hardening of coarse-grained hardened and unhardened samples, as well as in a change of a final diameters of the inside hole, which is indicative of the material deformability. suggests that the previous shock-wave hardening of coarse-grained samples brings their behaviour nature during collapse closer to the deformation mechanism of the finer-grained material. The previous shockwave loading and the following high-rate deformation lead to the block structure formation, which defines previous progress of the intergrain strain structure (Fig. 1).

Notice that the structure formation in the previous hardened fine-grained samples during the high-rate deformation is caused by an additional energy dissipation which, on the one hand, provides for a conserving the deformation uniformity to larger values of $\varepsilon$, and, on the other hand, leads to earlier stopping the inside hole surface motion, i. e. decreasing a general deformation. However, in the coarse-grained samples. owing to the intergrain block structure formation, the effect of grain boundaries decreases, and deformabiity of material improves.

\section{CONCLUSIONS}

1. The shock wave loading produces a high density of defects in the material, which favours thereatitur the dispersive intergrain structure formation during the following high-rate plastic strain.

2. In the previous hardened samples the deformation uniformity is conserved to the larger values of strain.

3. The following moderate deformation $(0.09-0.69)$ of shock-hardened samples leads to softemiger which can be due to forming of low-energy dislocation structure (LEDS).

4. The differences in the structure and deformability of coarse-grained hardened and unharderwed samples indicates that the previous hardening brings the nature of their behavior during the follown tate deformation closer to samples having an initial fine-grained structure. 


\section{REFERENCES}

[1] Nesterenko V.F., Bondar M.P., DYMAT Joumal, 1994, 1, N 3, pp. 245 -- 251.

[2] Ferreyra E., Murr L.E., Horz F., Metallurgical and Material Applications of Shock-Wave High-StrainRate Phenomena, L.E. Murr, K.P. Staudhammer and M.A. Meyers Eds., (Elsevier Science Publ., 1995), pp. $303-312$.

[3] Gourdin W.H., Shock-Wave and High-Strain-Rate Phenomena in Materials, M.A. Meyers, L.E. Murr and K.P. Staudhammer Eds., (Marcel Dekker, Inc. 1992), pp. 597 -- 609.

[4] Bondar M.P., Nesterenko V.F., J. de Physique, 3, V. 1, Oct. 1991, c.3 - 163 - c.3 - 170.

[5] Deribas A.A., Nesterenko V.F., Sapozhnikov G.A., Teslenko T.S., Fomin V.M., FGV, 1979, 2, pp. 126.

[6] Mendelson A, Plasticity: Theory and Application, (Krieger, Malabar, FL, 1968). 